\title{
Rendimento e Comportamento Espectrofotométrico da Lignina Extraída de Preparações de Parede Celular, Fibra em Detergente Neutro ou Fibra em Detergente Ácido
}

\author{
Nancy Maria de Fátima Savioli¹, Romualdo Shigueo Fukushima², César Gonçalves de Lima ${ }^{3}$, \\ Catarina Abdalla Gomide ${ }^{4}$
}

\begin{abstract}
RESUMO - A lignina extraída da planta forrageira peloreagente brometo de acetila (lignina brometo de acetila-LBrAc), para serempregada como padrão de referência no método espectrofotométrico para a determinação quantitativa da lignina, não pode originar-se da planta intacta, devido à interferência de diversas outras substâncias, que absorvem no mesmo comprimento de onda que a lignina; aconselha-se, portanto, que a extração da lignina seja realizada a partir de um dos seguintes compostos: parede celular propriamente dita (PC), fibra em detergente neutro (FDN) ou fibra em detergente ácido (FDA). Os rendimentos das extrações das ligninas, bem como o comportamento espectrofotométrico das mesmas, foram avaliados nestes três compostos provenientes de diversas plantas forrageiras. Na média, os rendimentos das extrações de LBrAc foram relativamente uniformes entre si, entretanto, como a concentração de FDA foi a menor entre todas as preparações (devido principalmente à solubilização da hemicelulose) e como esta não apresentou maior capacidade extrativa da lignina, o rendimento de LBrAc proveniente da FDA, com base na planta inteira, foi o menor observado. A absorção da luz ultravioleta das diversas ligninas foi desigual, revelada pelos espectrogramas traçados, de tal modo a sugerir que a preparação de parede celular adotada para o isolamento da lignina deve ser a mesma para a determinação final da concentração de lignina.
\end{abstract}

Palavras-chave: fibra em detergente neutro, fibra em detergente ácido, lignina brometo de acetila, método espectrofotométrico, parede celular

\section{Yield and Spectrophotometric Pattern of Lignin Extracted from Cell Wall, Neutral Detergent Fiber or Acid Detergent Fiber}

\begin{abstract}
The lignin extracted from the forages by the acetyl bromide reagent (acetyl bromide lignin - AcBrL) to be used as a reference standard for the quantitative spectrophotometric determination of lignin could not originate from intact plant because of interference of other substances, which absorb ultraviolet light at the same wavelength of lignin. It is then recommended that lignin extraction be performed in one of the following materials: cell wall itself (CW), neutral detergent fiber (NDF), or acid detergent fiber (ADF). The lignin extraction yields as well as the spectrographic pattern of those were evaluated in these three compounds that came from diverse forage plants. On the average, extraction yields of $\mathrm{AcBrL}$ were fairly uniform among them; however as the concentration of ADF was the lowest among all preparations (mainly due to hemicellulose solubilization) and as far this preparation did not exhibit higher lignin extraction capacity, the AcBrL concentration from ADF on a whole plant basis was the lowest observed. The ultraviolet light absorption from the diverse lignin was unequal, as revealed by the graphic spectrograms, which would suggest that the cell wall preparation used for lignin isolation must be the same for the final determination of lignin concentration.
\end{abstract}

Key Words: acetyl bromide lignin, acid detergent fiber, cell wall, neutral detergent fiber, spectrophotometric method

\section{Introdução}

A lignina é um composto fenólico existente na parede celular de vegetais e normalmente considerada indigestível pelos animais mamíferos (VAN SOEST, 1994). Além disso, a lignina, por mecanismos ainda discutidos (DEHORITY e JOHNSON, 1961; HARTLEY e JONES, 1977; e MORRISON, 1983), inibe consideravelmente a digestibilidade dos consti- tuintes da parede celular de plantas forrageiras e, por esta razão, tem sido útil na estimativa da extensão da digestão da fibra (AKIN et al., 1977; JUNG e VOGEL, 1986). No entanto, qualquer estimador de digestibilidade precisa ser determinado quimicamente com níveis aceitáveis de precisão e acurácia (FAICHNEY, 1975).

Análises laboratoriais de plantas forrageiras são necessárias para estimar a qualidade nutritiva das

\footnotetext{
${ }^{1}$ Bióloga, aluna de pós-graduação em Qualidade e Produtividade Animal, da Faculdade de Zootecnia e Engenharia de Alimentos da Universidade de São Paulo (FZEA-USP). Bolsista da FAPESP.

2 Médico-Veterinário, Professor do Departamento de Zootecnia da FZEA-USP. Av. Duque de Caxias Norte, 225 CEP - 13630-000 Pirassununga, SP. E.mail: rsfukush@usp.br; tel.: (19)561-2044.

${ }^{3}$ Estatístico, Professor do Departamento de Ciências Básicas da FZEA-USP.

${ }^{4}$ Farmacêutica, Professor do Departamento de Zootecnia da FZEA-USP.
} 
mesmas, e naturalmente é dada grande importância a fatores que limitam a digestibilidade dos nutrientes, como a lignina e outros componentes da parede celular de plantas (VAN SOEST e ROBERTSON, 1980). Entre os métodos laboratoriais empregados para quantificar o conteúdo de lignina em plantas forrageiras, situam-se os métodos gravimétricos lignina em detergente ácido (LDA) e lignina permanganato de potássio (LPer), descritos por VAN SOEST (1963) e VAN SOEST e WINE (1968), respectivamente. Entretanto, estes métodos têm recebido sérias críticas; por exemplo, a LDA usualmente subestima a concentração de lignina, possivelmente pela parcial solubilização da mesma nas soluções empregadas no método (SHIMOJO e GOTO, 1984; HATFIELD et al., 1994) e, por outro lado, a LPer pode estar superestimando os teores de lignina, se ocorrer a oxidação de outras estruturas da parede celular pelo permanganato de potássio (BARTON II e AKIN, 1977). MORRISON (1972a,b) propôs um método espectrofotométrico para quantificar a lignina em plantas forrageiras, o qual poderia oferecer resultados mais satisfatórios que os métodos gravimétricos; este método baseia-se na solubilização da lignina em uma solução de brometo de acetila a $25 \%$ em ácido acético glacial, sendo esta então mensurada no comprimento de onda a $280 \mathrm{~nm}$. Entretanto, como em qualquer método espectrofotométrico, este também requer o emprego de um padrão de referência e, a partir da curva de calibração, avaliar o conteúdo da substância de interesse (FENGEL e WEGENER, 1989).

Vários compostos foram anteriormente empregados como padrão de referência - lignina dioxana (PEPPER, 1959), lignina moída de madeira (BJORKMAN, 1956), lignina "kraft" de faia (BRILLOVET e RIOCHET, 1983), guaiacol (SHARMA et al., 1986), ácido ferúlico (AL-ANI e SMITH, 1988), lignina nativa de alfafa (FUKUSHIMA et al., 1991) e até mesmo um fator numérico, o coeficiente específico de absorção (IIYAMA e WALLIS, 1990). LOWRY et al. (1994) tentaram empregar a lignina em detergente ácido (LDA) como padrão de referência, com resultados infrutíferos.

Nenhuma das tentativas de relacionar dados de densidade óptica provenientes dos padrões de referência supramencionados, para a obtenção da concentração de lignina na planta forrageira, foi plenamente satisfatória; a principal razão reside no fato de que é altamente desejável que o padrão de referência seja uma cópia a mais próxima possível da substância sendo analisada. Recentemente,
FUKUSHIMA e DEHORITY (no prelo) lograram em extrair uma lignina por meio do reagente brometo de acetila-substância denominada de lignina brometo de acetila (LBrAc) e empregada como padrão de referência na análise espectrofotométrica.

Para a extração de lignina, é de fundamental importância que a amostra vegetal seja isenta de contaminantes que absorvam no mesmo comprimento de onda da lignina, como polifenóis, taninos, lignóides, aminoácidos aromáticos etc (MORRISON, 1972a). Por esta razão, a extração da lignina não deve ser realizada na planta intacta, recomendando-se materiais como a fibra em detergente neutro (FDN) ou a fibra em detergente ácido (FDA), ambas descritas por GOERING e VAN SOEST (1970), ou na preparação de parede celular (PC), descrita por IIYAMA e WALLIS (1990).

Este projeto de pesquisa visou aprimorar a técnica de extração da lignina pelo reagente brometo de acetila, ao subsidiar a escolha do melhor material para a recuperação quantitativa da lignina brometo de acetila, sendo basicamente três as preparações: PC, FDN e FDA.

\section{Material e Métodos}

As extrações da lignina pelo reagente brometo de acetila foram realizadas no Laboratório de Lignina da Faculdade de Zootecnia e Engenharia de Alimentos da Universidade de São Paulo (FZEA-USP), em Pirassununga, SP. As amostras de plantas forrageiras foram obtidas no campo agrostológico da FZEAUSP, no estádio "maduro" (ou seja, com todas as sementes formadas e mais que a metade das folhas mortas), cortadas a $10 \mathrm{~cm}$ do solo, submetidas à secagem em estufa ventilada a $65^{\circ} \mathrm{C}$, por 72 horas, e moídas em moinho Wiley munido com peneira de $1 \mathrm{~mm}$. Foram analisadas as seguintes forrageiras: Alfafa (Medicago sativa); Aveia forrageira (Avena sativa); Brizanta (Brachiaria brizanta); Centenário (Panicum maximum cv. Centenário); Colonião (Panicum maximum cv. Colonião); Napier (Pennisetum purpureum cv. Napier); e Pangola (Digitaria decumbens).

O procedimento para a extração da lignina, com o emprego do brometo de acetila (FUKUSHIMA e DEHORITY, no prelo), é sucintamente descrito a seguir: foi adotado o critério de se manter constante a quantidade de material vegetal inicial, com base na matéria seca (quatro gramas), e a seguir foram realizados os procedimentos laboratoriais para a 
990 Rev. bras. zootec.

obtenção da PC, FDN e FDA. Certa quantidade de preparação de parede celular foi pesada em um tubo de teflon com tampa de rosquear, sendo em seguida pipetados $35 \mathrm{~mL}$ de uma solução a $25 \%$ de brometo de acetila em ácido acético glacial; o tubo foi fechado, agitado e aquecido em banho maria a $70^{\circ} \mathrm{C}$ por 30 min com agitação a cada 15 min. Após a digestão, o material foi centrifugado a 3000 rotações por minuto durante 15 min e o sobrenadante, colocado em um erlenmeyer de um litro e mantido em um banho de gelo por cinco minutos; a seguir, inverteu-se sobre a solução aproximadamente $900 \mathrm{~mL}$ de água destilada gelada, ocorrendo, assim, a precipitação da lignina dissolvida. A mesma foi então separada por filtração a vácuo, utilizando-se papel-filtro Whatman $\mathrm{n}^{\mathrm{o}} 4$, e o resíduo, lavado com $300 \mathrm{~mL}$ de água destilada, sofrendo, a seguir, parcial desidratação em estufa ventilada a $45^{\circ} \mathrm{C}$. Este resíduo foi solubilizado em dioxana $(30 \mathrm{~mL})$ e novamente precipitado pela adição de água destilada $(900 \mathrm{~mL})$, formando então uma solução de aspecto coloidal; adição de três gramas de sulfato de sódio anidro auxiliou no processo de floculação do material, sendo o mesmo filtrado, lavado e parcialmente desidratado. Este resíduo foi novamente solubilizado em dioxana (cerca de $30 \mathrm{~mL}$ ) e a recuperação final da lignina ocorreu por precipitação, quando esta solução de dioxana foi gotejada sobre uma solução de éter etilico anidro/éter de petróleo (80:20), sob constante agitação. Após filtrar em uma membrana de nylon (porosidade $0,45 \mu$ ), o filtrado foi lavado com $80 \mathrm{~mL}$ de éter de petróleo e seco em estufa ventilada a $45^{\circ} \mathrm{C}$, obtendo-se, assim, a lignina brometo de acetila ( $\mathrm{LBrAc})$.

As determinações de proteína bruta nas amostras de LBrAc seguiram os preceitos da ASSOCIATION OF OFFICIAL ANALYTICAL CHEMISTS AOAC (1980) e as determinações de carboidrato pela técnica da antrona, descrita por VILES JR. e SILVERMAN (1949). As análises estatísticas referentes aos rendimentos das extrações de lignina e respectivos teores de carboidratos e proteína foram conduzidas utilizando-se o teste Tukey, a 5\%. Os dados foram analisados com o auxílio do pacote estatístico SAS (STATISTICAL ANALYSIS SYSTEM - SAS, 1985).

Foi construída uma curva padrão para cada lignina isolada nas três preparações de parede celular. Todas as curvas foram lineares nas concentrações testadas. Para a confecção da curva padrão, foram pesados $30 \mathrm{mg}$ de LBrAc (com as devidas correções para os teores de carboidratos e proteína) em um tubo de teflon com tampa de rosquear e, a seguir, adicionados $4 \mathrm{~mL}$ da solução a $25 \%$ de brometo de acetila. A solução foi aquecida em banho-maria a $70^{\circ} \mathrm{C}$ por 30 min. Após, o tubo foi esfriado em água corrente $\mathrm{e}$ adicionados $26 \mathrm{~mL}$ de ácido acético glacial (HAc). $\mathrm{Na}$ seqüência, foi preparada uma série de 10 tubos, inclusive um branco, cada um deles contendo $6 \mathrm{~mL}$ de HAc mais $4 \mathrm{~mL}$ de $\mathrm{NaOH}$ 0,3 M. Foram pipetadas alíquotas crescentes provenientes do tubo contendo a $\mathrm{LBrAc}$ e, a seguir, acrescentou-se $1 \mathrm{~mL}$ de uma solução $0,5 \mathrm{M}$ de cloridrato de hidroxilamina em cada tubo. O volume final foi completado para $25 \mathrm{~mL}$ com HAc e realizadas as leituras de densidade óptica no comprimento de onda, a 280 nanometros (nm), em um espectrofotômetro da marca Milton Roy, modelo Genesis II.

\section{Resultados e Discussão}

A extração da lignina do material vegetal, por meio do reagente brometo de acetila, não deve ser feita na planta intacta, e sim em algum material cujo conteúdo celular (citoplasma e seus componentes) tenha sido removido, com a finalidade de eliminar substâncias que interferem na absorção da luz ultravioleta no comprimento de onda a $280 \mathrm{~nm}$ (MORRISON, 1972a). Os valores de parede celular (PC), fibra em detergente neutro (FDN) e fibra em detergente ácido (FDA) podem ser observados na Tabela 1. Os valores de PC e FDN foram próximos entre si (ligeiramente inferiores para a FDN), variando de 50,7 a $77,8 \%$ para a PC e de 40,2 a $75,1 \%$ para a preparação FDN, e superiores aos rendimentos de FDA, que variaram entre 25,9 e 43,7\%. Embora não tenha sido feita a análise estatística, pode-se observar que, para todos os materiais, a Alfafa foi a que ofereceu o menor valor e o capim Colonião, o maior. Esta observação está de acordo com a descrição de VAN SOEST (1994), na qual as leguminosas em geral apresentam menores teores de holocelulose em comparação às gramíneas. A diferença observada entre as preparações PC/FDN e FDA deve-se, provavelmente, à solubilização da hemicelulose - constituinte que não está presente na FDA (GOERING e VAN SOEST, 1970). Empiricamente, tem-se adotado a diferença FDN - FDA para obtenção dos teores de hemicelulose, entretanto, valores obtidos dessa maneira devem ser considerados como presumidos, uma vez que a FDA pode ainda apresentar resíduos de pentosanas (MORRISON, 1983), bem como mostrar presença de pectina, importante integrante da parede celular de certas espécies vegetais, particularmente as 
Tabela 1 - Valores de parede celular, fibra em detergente neutro e fibra em detergente ácido, na base da matéria seca, das diferentes espécies forrageiras ${ }^{1}$

Table 1 - Values of cell wall, neutral detergent fiber and acid detergent fiber, on a dry matter basis, from different forage species ${ }^{1}$

\begin{tabular}{lccc}
\hline $\begin{array}{l}\text { Amostra } \\
\text { Sample }\end{array}$ & PC & FDN & FDA \\
Alfafa & 50,7 & 40,2 & 25,9 \\
$\begin{array}{l}\text { Alfalfa } \\
\text { Aveia } \\
\text { Oat }\end{array}$ & 64,6 & 63,3 & 32,7 \\
$\begin{array}{l}\text { Brizanta } \\
\text { Brizantha grass }\end{array}$ & 71,4 & 68,9 & 39,4 \\
$\begin{array}{l}\text { Centenário } \\
\text { Centenario grass }\end{array}$ & 73,1 & 65,2 & 40,7 \\
$\begin{array}{l}\text { Colonião } \\
\text { Guinea grass }\end{array}$ & 77,8 & 75,1 & 43,7 \\
$\begin{array}{l}\text { Napier } \\
\text { Elephant grass }\end{array}$ & 69,6 & 62,5 & 41,7 \\
$\begin{array}{l}\text { Pangola } \\
\text { Pangola grass } \\
\text { Média }\end{array}$ & 68,3 & 65,5 & 36,3 \\
Mean & 67,9 & 63,0 & 37,2 \\
\hline $\begin{array}{l}\text { Valores expressos } \\
\text { Vem }\end{array}$ & & & \\
\hline
\end{tabular}

1 Valores expressos em porcentagem; PC - parede celular; FDN fibra em detergente neutro; FDA - fibra em detergente ácido.

1 Data are express in percentage; CW - cell wall; NDF- neutral detergent fiber; $A D F$ - acid detergent fiber.

leguminosas (VAN SOEST, 1994), e ainda existe a possibilidade de parte da lignina ter sido solubilizada pela solução de detergente ácido (SHIMOJO e GOTO, 1984).

Os rendimentos das extrações de lignina brometo de acetila ( $\mathrm{LBrAc}$ ), provenientes da PC, FDN e FDA, com base na matéria seca, podem ser visualizados na Tabela 2. O rendimento de $\mathrm{LBrAc}$ variou de 16,4 a $27,3 \%$ na PC; de 10,7 a $36,1 \%$ na FDN; e de 8,9 a $20,2 \%$ na FDA. Não foi constatada qualquer tendência de, em determinada preparação, o rendimento de LBrAc, para dada espécie vegetal, ser prevalente. Por exemplo, o rendimento de LBrAc proveniente da PC foi maior para o Napier em relação ao Pangola e à Alfafa $(p<0,05)$ e similar entre a Aveia, a Brizanta, o Centenário, o Colonião e o próprio Napier. Em relação ao rendimento de LBrAc proveniente da FDN, o Colonião mostrou valor significativamente superior $(\mathrm{p}<0,05)$ relativo às demais plantas forrageiras, à exceção da Aveia, enquanto a Alfafa foi a que exibiu o menor teor de LBrAc extraída. Quanto à FDA, a Brizanta foi a que rendeu a maior $(\mathrm{p}<0,05)$ concentração de LBrAc, situando-se em igualdade apenas em relação ao Pangola; das demais espécies forrageiras, foram extraídas quantidades similares de LBrAc.
Tabela 2 - Rendimento das extrações de lignina brometo de acetila proveniente da parede celular, da fibra em detergente neutro e da fibra em detergente ácido, com base na matéria seca ${ }^{1}$

Table 2 - Yield of acetyl bromide lignin extractions from cell wall, neutral detergent fiber and acid detergent fiber, on a dry matter basis ${ }^{1}$

\begin{tabular}{|c|c|c|c|}
\hline $\begin{array}{l}\text { Amostra } \\
\text { Sample }\end{array}$ & $\begin{array}{l}\mathrm{PC} \\
C W\end{array}$ & $\begin{array}{l}\text { FDN } \\
N D F\end{array}$ & $\begin{array}{l}\text { FDA } \\
A D F\end{array}$ \\
\hline Alfafa & $16,4^{\mathrm{C}, \mathrm{a}}$ & $10,7^{\mathrm{D}, \mathrm{a}}$ & $12,9^{\mathrm{B}, \mathrm{C}, \mathrm{a}}$ \\
\hline Alfalfa & & & \\
\hline $\begin{array}{l}\text { Aveia } \\
\text { Oat }\end{array}$ & $23,4^{\mathrm{A}, \mathrm{B}, \mathrm{b}}$ & $31,3^{\mathrm{A}, \mathrm{B}, \mathrm{a}}$ & $8,9^{\mathrm{C}, \mathrm{c}}$ \\
\hline $\begin{array}{l}\text { Brizanta } \\
\text { Brizantha grass }\end{array}$ & $25,1^{\mathrm{A}, \mathrm{B}, \mathrm{a}}$ & $22,1^{\mathrm{C}, \mathrm{a}}$ & $20,2^{\mathrm{A}, \mathrm{a}}$ \\
\hline $\begin{array}{l}\text { Brizantha grass } \\
\text { Centenário }\end{array}$ & $26,6^{\mathrm{A}, \mathrm{B}, \mathrm{a}}$ & $23,3^{\mathrm{C}, \mathrm{a}}$ & $12,1^{\mathrm{B}, \mathrm{C}, \mathrm{b}}$ \\
\hline $\begin{array}{l}\text { Centenario grass } \\
\text { Colonião }\end{array}$ & $21,9^{\mathrm{A}, \mathrm{B}, \mathrm{C}, \mathrm{b}}$ & $36,1^{\mathrm{A}, \mathrm{a}}$ & $9,3^{\mathrm{C}, \mathrm{c}}$ \\
\hline $\begin{array}{l}\text { Guinea grass } \\
\text { Napier }\end{array}$ & $27,3^{\mathrm{A}, \mathrm{a}}$ & $28,2 \mathrm{~B}, \mathrm{C}, \mathrm{a}$ & $11,5 \mathrm{~B}, \mathrm{C}, \mathrm{b}$ \\
\hline $\begin{array}{l}\text { Elephant grass } \\
\text { Pangola }\end{array}$ & $20,1^{\mathrm{B}, \mathrm{C}, \mathrm{a}, \mathrm{b}}$ & $24,1^{\mathrm{C}, \mathrm{a}}$ & $16,9^{\mathrm{A}, \mathrm{B}, \mathrm{b}}$ \\
\hline $\begin{array}{l}\text { Pangola grass } \\
\text { Média } \\
\text { Mean }\end{array}$ & 23,0 & 25,1 & 13,1 \\
\hline
\end{tabular}

1 Dados expressos em porcentagem; PC - parede celular; FDN fibra em detergente neutro; FDA - fibra em detergente ácido. Médias, na coluna, seguidas de letras maiúsculas diferentes são diferentes $(P<0,05)$ pelo teste Tukey.

Médias, na linha, seguidas de letras minúsculas diferentes são diferentes $(P<0,05)$ pelo teste Tukey.

1 Data are express in percentage; $C W$-cell wall; NDF-neutral detergent fiber; $A D F$ - acid detergent fiber.

Means, within a column, followed by different capital letters are different $(P<.05)$ by Tukey test.

Means, within a row, followed by different small letters are different $(P<.05)$ by Tukey test.

Como já mencionado anteriormente, não foi detectada uniformidade na extração da lignina entre as plantas forrageiras. Este comportamento não encontra explicação até o presente momento, e a presunção mais plausível é que os diferentes procedimentos de obtenção da PC, FDN e FDA induzem a modificações de ordem física e/ou química de tal maneira a interferir na extração. Quanto ao rendimento das extrações de LBrAc, a FDA, na maioria dos casos, rendeu menos LBrAc que a FDN e PC $(\mathrm{P}<0,05)$. Tal observação deve-se indubitavelmente aos menores valores de FDA na planta inteira.

É necessário considerar o fato de que a quantidade de amostra inicial foi a mesma para todas as preparações, assim, em tese, a concentração inicial de lignina foi a mesma para todas as extrações. Apesar de usualmente considerar-se que apenas a hemicelulose é a única substância que se solubiliza na solução de detergente ácido, uma plausível explicação para esse 
992

Rev. bras. zootec

menor rendimento de lignina foi a oferecida por SHIMOJO e GOTO (1984), os quais reportaram que parte da lignina também seria solubilizada durante a preparação da FDA. Aparentemente a FDA não seria, portanto, o melhor material objetivando a extração de LBrAc.

FUKUSHIMA et al. (1991) extraíram lignina com etanol em amostras de alfafa, obtendo rendimentos menores a $1 \%$ da matéria seca, possivelmente pela ineficiência da extração alcoólica. ROSSINI et al. (1989) empregaram diversos solventes (metanol, etanol, acetona, dioxana, acetonitrilo, dimetilformamida e trietilenoglicol) para extrair a lignina da serragem do Pinus caribaea hondurensis, obtendo rendimentos de 2,0 a 6,6\% do peso seco da madeira. Extração de lignina variando de 1,1 a $24,4 \%$ da matéria seca foi obtida por BALOGH et al. (1989), quando empregaram outros solventes (clorofórmio, acetona, dioxana, tetrahidrofurano, 2-butanol, 1-butanol, 1-propanol, etanol e metanol), entretanto, os maiores rendimentos só foram obtidos mediante catálise por ácido mineral.

FUKUSHIMA e DEHORITY (no prelo) e FUKUSHIMA et al. (no prelo) obtiveram menores rendimentos na extração de $\mathrm{LBrAc}$ proveniente da preparação parede celular de plantas forrageiras em estádio de maturidade semelhante, cujos valores variaram de 5,1 a $14,4 \%$ na matéria seca da planta inteira, provavelmente devido à menor quantidade do reagente brometo de acetila, empregado em relação à quantidade de amostra. Nesse experimento, a extração da lignina pelo reagente brometo de acetila possivelmente solubilizou maior fração da lignina total, uma vez que foram obtidos rendimentos mais elevados que os autores anteriormente citados; entretanto, ainda é questionável se a totalidade da lignina, ou a quase totalidade da mesma, é passível de ser extraída e recuperada. Se esses dados numéricos de extração fossem comparados com metodologias para quantificar lignina, seriam mais próximos à LDA e sensivelmente inferiores aos valores de lignina solúvel em brometo de acetila reportados na literatura, por exemplo, os dados obtidos por SHIMOJO e GOTO (1984) e IIYAMA e WALLIS (1990). Algumas explicações plausíveis residiriam em algum (ou alguns) dos seguintes aspectos: 1. na possibilidade de que a capacidade extrativa do reagente brometo de acetila foi a máxima, como poderia ser o caso do presente experimento, e, portanto, os dados de lignina brometo de acetila reportados na literatura estariam superestimados; 2. na possibilidade de o reagente brometo de acetila solubilizar toda a lignina, entretanto, nas etapas subseqüentes não for possível a recuperação quantitativa de sua totalidade, por exemplo, pequenas estruturas derivadas da lignina (monômeros e dímeros) e/ou cadeias carbônicas acetiladas durante a digestão com o brometo de acetila, que permaneceriam solúveis na solução aquosa, não sendo, portanto, recuperadas durante o processo de filtração; 3 . estas estruturas hidrossolúveis, apesar de nãoquantitativamente recuperáveis, seriam responsáveis, em conjunto com o restante da lignina, por intensa absorbância no comprimento de onda a $280 \mathrm{~nm}$, explicando, portanto, os altos valores de lignina solúvel em brometo de acetila reportados na literatura; 4. existe ainda a possibilidade de o reagente brometo de acetila não ser capaz de extrair a totalidade, ou quase, da lignina; entretanto, esta hipótese não parece ser provável, sendo já demonstrado anteriormente que o resíduo da centrifugação, após o passo da digestão no brometo de acetila, mostrou insignificantes picos de absorção no intervalo de 240 a $320 \mathrm{~nm}$ (FUKUSHIMA e DEHORITY, no prelo).

Curvas de regressão linear das LBrAc extraídas da PC, FDN ou FDA de três plantas forrageiras (escolhidas ao acaso) estão na Figura 1. Apesar de o comportamento espectrográfico da LBrAc do capim Colonião ter sido muito semelhante entre a PC, FDN e FDA, o padrão espectrográfico das gramíneas Aveia e Napier foi diferente em cada uma das preparações. A falta de padrão regular, quando das extrações das diversas LBrAc, é condizente com esta última observação.

Constata-se na Figura 2 que o comportamento espectrográfico das ligninas foi diferente entre PC, FDN ou FDA, exceto para o Colonião. Esta variabilidade no comportamento espectrográfico, como já mencionado anteriormente, deve-se provavelmente aos diferentes procedimentos para a obtenção da PC, FDN e FDA. Isso significa que, quando se optar por determinado material objetivando a extração de LBrAc, este deve ser necessariamente o mesmo a ser empregado no método analítico, quando da análise quantitativa final do teor de lignina na planta forrageira.

Teores de carboidratos (CHO) e proteína bruta (PB) das diversas LBrAc constam da Tabela 3. O teor de carboidratos na $\mathrm{LBrAc}$ proveniente da $\mathrm{PC}$ variou de 1,4 a $3,2 \%$; da FDN, de 1,6 a 2,6\%; e da FDA, de 1,1 a $3,1 \%$. Referente às concentrações de CHO dentro da PC ou FDA (não houve diferença estatística para a fração FDN), observou-se maior concentração de $\mathrm{CHO}$ no Pangola em comparação ao Colonião $(\mathrm{P}<0,05)$, tanto para a $\mathrm{PC}$, como para a 
SAVIOLI et al.

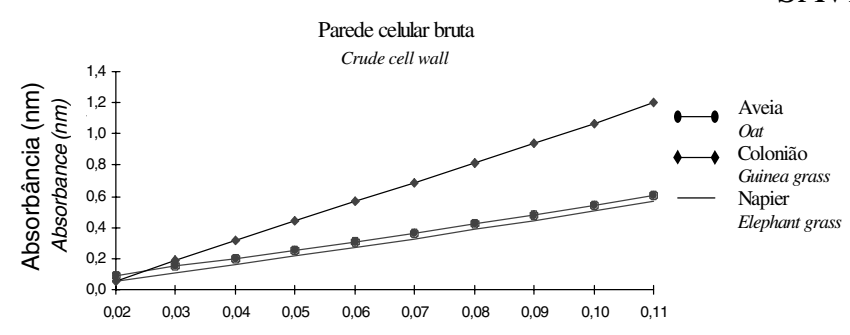

Concentração (mg/mL)

Concentration ( $\mathrm{mg} / \mathrm{mL}$ )

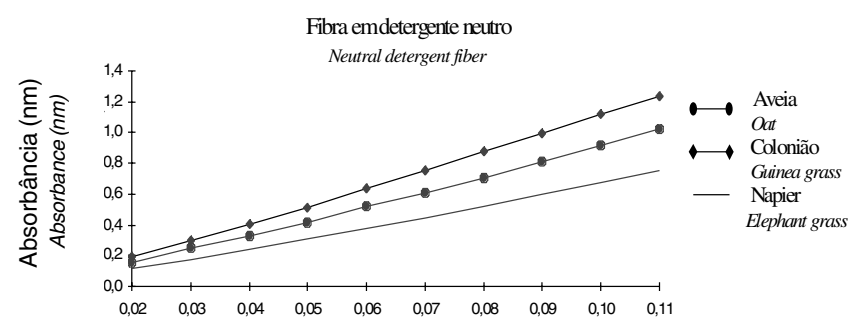

Concentração $(\mathrm{mg} / \mathrm{mL})$

Concentration $(\mathrm{mg} / \mathrm{mL})$

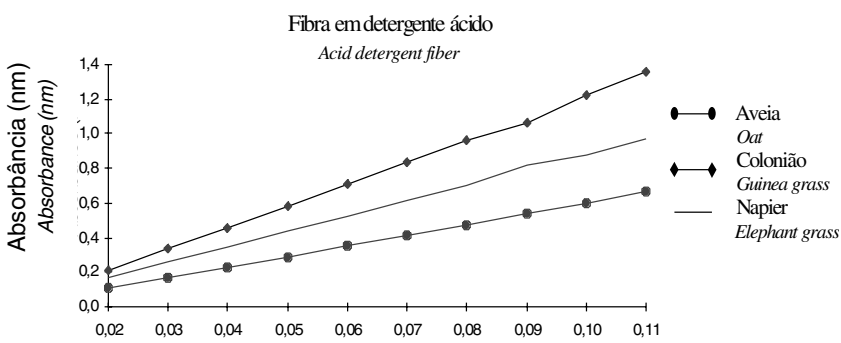

Concentração $(\mathrm{mg} / \mathrm{mL})$

Concentration $(\mathrm{mg} / \mathrm{mL})$

Figura 1 - Curvas de regressão linear da lignina brometo de acetila proveniente da parede celular, da fibra em detergente neutro e da fibra em detergente ácido de três forrageiras.

Figure 1 - Linear regression curves of acetyl bromide lignins from cell wall, neutral detergent fiber and acid detergent fiber of three forages.
Lignina brometo de acetila da aveia

Oats acetyl bromide lignin

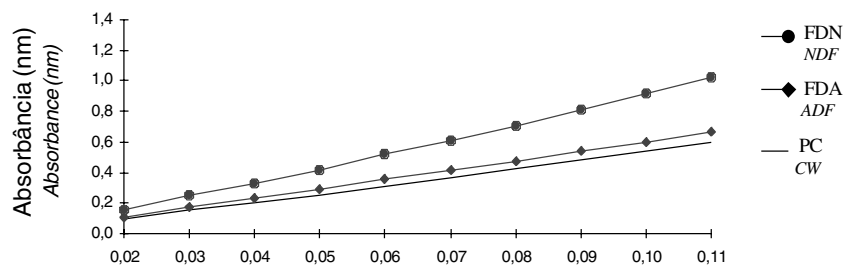

Concentração (mg/mL)

Concentration $(\mathrm{mg} / \mathrm{mL})$

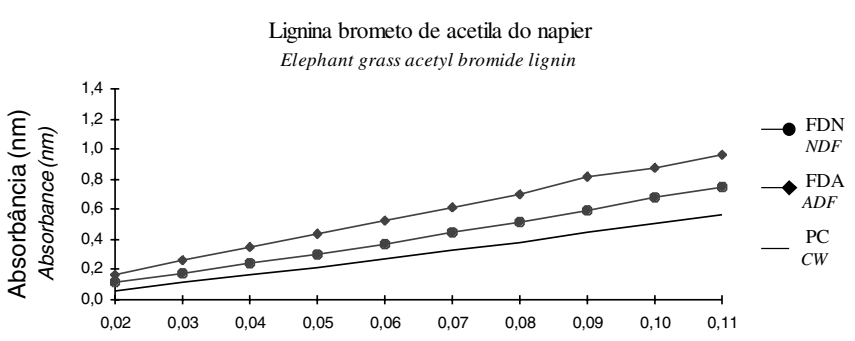

Concentração (mg/mL)

Concentration $(\mathrm{mg} / \mathrm{mL})$

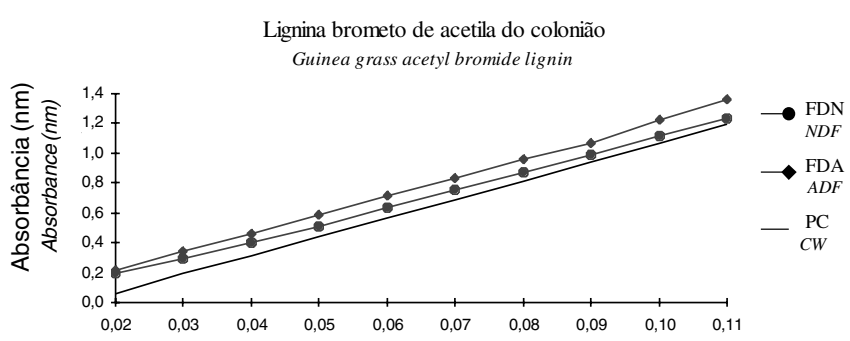

Concentração $(\mathrm{mg} / \mathrm{mL})$

Concentration $(\mathrm{mg} / \mathrm{mL})$

Figura 2 - Curvas de regressão linear da lignina brometo de acetila proveniente de diferentes preparações de parede celular da planta forrageira.

Figure 2 - Linear regression curves of acetyl bromide lignins from different cell wall preparations of each forage species. 
994 Rev. bras. zootec.

FDA. De modo geral, não se observaram grandes diferenças nos teores de $\mathrm{CHO}$, entre as espécies vegetais, exceto o Colonião. Dentro de cada espécie vegetal, não foram detectadas diferenças estatísticas entre a PC, FDN e FDA. Obtenção de uma lignina relativamente pura em quantidades apreciáveis não é tarefa fácil (IIYAMA e WALLIS, 1990). A lignina é covalentemente ligada à fração carboidrato da parede celular, em particular à hemicelulose, e se acentua à medida que as plantas forrageiras amadurecem, sendo esta uma das possíveis causas a explicar a baixa digestibilidade da parede celular de plantas maduras (MORRISON, 1973). FUKUSHIMA (1989), ao examinar algumas formas de lignina "kraft", verificou a presença de 10,3 a 11,2\% de CHO, enquanto a lignina obtida da alfafa apresentou $15,5 \%$ de CHO. FUKUSHIMA e DEHORITY (no prelo) e FUKUSHIMA et al. (no prelo) obtiveram teores mais elevados de $\mathrm{CHO}$, que variaram de 7,3 a 29,7\% nas espécies botânicas. Observa-se, então, que no presente estudo os teores de $\mathrm{CHO}$ foram sensivelmente menores que os reportados na literatura, e possíveis explicações residiriam em diferentes condi- ções laboratoriais ou em características inerentes às próprias plantas forrageiras.

Os teores de PB variaram de 2,6 a 10,0\% na PC, de 2,1 a $6,3 \%$ na FDN e de 1,1 a 3,0\% na FDA. Com respeito às concentrações de $\mathrm{PB}$, dentro dos materiais estudados, não foi observada qualquer tendência de determinada LBrAc apresentar maior ou menor teor de PB; destaca-se apenas a significativa presença de PB na amostra de lignina do capim Centenário na $\mathrm{PC}$, o que não se repetiu com a mesma magnitude nas demais frações. A explicação mais plausível pode ser atribuída à maior ou menor capacidade extrativa das soluções empregadas, pois, para o preparo da PC, utilizam-se água quente e solventes orgânicos (álcool e clorofórmio), enquanto, para a obtenção da FDN e FDA, são empregadas soluções de detergente. Uma das finalidades da solução de detergente ácido utilizada para o preparo da FDA, preconizada por VAN SOEST (1963), é dissolver a proteína contida na parede celular; no presente trabalho, foi a fração a apresentar para a maioria dos casos, o menor teor de PB nas LBrAc $(\mathrm{P}<0,05)$. HATFIELD et al. (1994) reportaram que, no geral, ligninas prove-

Tabela 3 - Teores de carboidrato e de proteína na lignina brometo de acetila proveniente da parede celular, da fibra em detergente neutro e da fibra em detergente ácido ${ }^{1}$

Table 3 - Concentration of carbohydrate and protein of acetyl bromide lignin from cell wall, neutral detergent fiber and acid detergent fiber ${ }^{1}$

\begin{tabular}{|c|c|c|c|c|c|c|}
\hline \multirow{3}{*}{$\begin{array}{l}\text { Amostra } \\
\text { Sample }\end{array}$} & \multicolumn{3}{|c|}{$\begin{array}{l}\text { Carboidrato } \\
\text { Carbohydrate }\end{array}$} & \multicolumn{3}{|c|}{$\begin{array}{l}\text { Proteína } \\
\text { Protein }\end{array}$} \\
\hline & $\mathrm{PC}$ & FDN & FDA & $\mathrm{PC}$ & FDN & FDA \\
\hline & $C W$ & $N D F$ & $A D F$ & $C W$ & $N D F$ & $A D F$ \\
\hline Alfafa & $2,8^{\mathrm{A}, \mathrm{B}}$ & 2,5 & $3,1^{\mathrm{A}}$ & $5,2^{\mathrm{B}, \mathrm{a}}$ & $3,5^{\mathrm{B}, \mathrm{C}, \mathrm{b}}$ & $2,2^{\mathrm{A}, \mathrm{B}, \mathrm{C}, \mathrm{C}}$ \\
\hline $\begin{array}{l}\text { Alfalfa } \\
\text { Aveia }\end{array}$ & $3,0^{\mathrm{A}}$ & 2,2 & $2,5^{\mathrm{A}, \mathrm{B}}$ & $3,0^{\mathrm{C}, \mathrm{D}, \mathrm{a}}$ & $3,5^{\mathrm{B}, \mathrm{C}, \mathrm{a}}$ & $1,7^{\mathrm{B}, \mathrm{C}, \mathrm{a}}$ \\
\hline $\begin{array}{l}\text { Oat } \\
\text { Brizanta } \\
\text { Brizantha grass }\end{array}$ & $2,4^{\mathrm{A}, \mathrm{B}}$ & 2,5 & $2,6^{\mathrm{A}, \mathrm{B}}$ & $2,6^{\mathrm{D}, \mathrm{a}}$ & $2,1^{\mathrm{C}, \mathrm{b}}$ & $1,2^{\mathrm{C}, \mathrm{b}}$ \\
\hline $\begin{array}{l}\text { Brizantha grass } \\
\text { Centenário } \\
\text { Centenario grass }\end{array}$ & $2,0^{\mathrm{A}, \mathrm{B}}$ & 2,6 & $2,5^{\mathrm{A}, \mathrm{B}}$ & $10,0^{\mathrm{A}, \mathrm{a}}$ & $3,6^{\mathrm{B}, \mathrm{b}}$ & $3,0^{\mathrm{A}, \mathrm{b}}$ \\
\hline Colonião & $1,4^{\mathrm{B}}$ & 1,6 & $1,1^{\mathrm{B}}$ & $4,9^{\mathrm{B}, \mathrm{C}, \mathrm{a}}$ & $3,4^{\mathrm{B}, \mathrm{C}, \mathrm{b}}$ & $2,0^{\mathrm{A}, \mathrm{B}, \mathrm{C}, \mathrm{C}}$ \\
\hline $\begin{array}{l}\text { Guinea grass } \\
\text { Napier } \\
\text { Elephant grass }\end{array}$ & $2,4^{\mathrm{A}, \mathrm{B}}$ & 2,6 & $2,3^{\mathrm{A}, \mathrm{B}}$ & $3,0^{\mathrm{C}, \mathrm{D}, \mathrm{a}}$ & $2,7^{\mathrm{B}, \mathrm{C}, \mathrm{a}}$ & $2,6^{\mathrm{A}, \mathrm{B}, \mathrm{a}}$ \\
\hline $\begin{array}{l}\text { Pangola } \\
\text { Pangola grass }\end{array}$ & $3,2^{\mathrm{A}}$ & 2,5 & $3,0^{\mathrm{A}}$ & $5,1^{\mathrm{B}, \mathrm{a}}$ & $6,3^{\mathrm{A}, \mathrm{a}}$ & $1,1^{\mathrm{C}, \mathrm{b}}$ \\
\hline
\end{tabular}

1 Dados expressos em porcentagem; PC - parede celular; FDN - fibra em detergente neutro; FDA - fibra em detergente ácido.

Médias, na coluna, seguidas de letras maiúsculas diferentes são diferentes $(P<0,05)$ pelo teste Tukey.

Médias, na linha, seguidas de letras minúsculas diferentes são diferentes $(P<0,05)$ pelo teste Tukey.

1 Data are express in percentage; CW - cell wall; NDF - neutral detergent fiber; ADF - acid detergent fiber.

Means, within a column, followed by different capital letters are different $(P<.05)$ by Tukey test.

Means, within a row, followed by different small letters are different $(P<.05)$ by Tukey test. 
nientes de gramíneas exibiram maiores teores de PB que a lignina da alfafa. Entretanto, no presente trabalho, não foi constatada essa observação. FUKUSHIMA (1989) reduziu a concentração de N de 3,6 para $0,8 \%$, com infusão em água quente ou extração alcoólica de lignina "kraft", e a esta relativa facilidade na remoção de $\mathrm{N}$ poderia ser creditada a não-existência de ligações químicas entre lignina e proteína (MORRISON, 1973). Entretanto, permanece ainda a questão se o $\mathrm{N}$ é parte constituinte da molécula de lignina, ou se está presente na forma de proteína como contaminante ou não. McDOUGALL et al. (1996) mencionaram, em uma revisão sobre parede celular, alguns resultados de pesquisas, nos quais se reconhece a presença de proteínas, sendo a principal denominada de extensina, uma glicoproteína na qual predominam os aminoácidos hidroxiprolina, lisina e serina (WILSON e FRY, 1986). Diferentemente do descrito por MORRISON (1973), aparentemente a inter-relação entre parede celular e proteínas é bem mais complexa (CARPITA e GIBEAUT, 1993). Entretanto, lignina extraída de madeira (eucalipto) revelou praticamente total ausência de proteína (FUKUSHIMA e DEHORITY, no prelo).

\section{Conclusões}

Com base no rendimento das extrações de LBrAc, aparentemente as preparações PC e FDN mostraram-se como as mais eficazes.

A escolha de determinado material, objetivando a extração da lignina brometo de acetila, deverá ser no sentido de que a determinação quantitativa da lignina também seja realizada nesse mesmo material.

\section{Agradecimento}

À Fundação de Amparo à Pesquisa do Estado de São Paulo (FAPESP), pelo auxílio financeiro (processo número 95/3798-3) concedido, que possibilitou a execução da pesquisa, ora representada, em parte, no presente artigo. Agradecemos também pela Bolsa de Mestrado (processo número 96/07167-0) concedida à primeira autora.

\section{Referências Bibliográficas}

AKIN, D.E., ROBINSON, E.L., BARTON II, F.E. et al. 1977. Change with maturity in anatomy, histochemistry, chemistry and tissue digestibility of bermudagrass parts. J. Agric. Food. Chem., 25:179.
AL-ANI, F., SMITH, J.E. 1988. Effect of chemical pretreatments on the fermentation and ultimate digestibility of bagasse by Phanerochaete chrysosporium. J. Sci. Food Agric., 42:19-28.

ASSOCIATION OF OFFICIAL ANALYTICAL CHEMISTS AOAC. 1990. Official methods of analysis. 15 ed. Washington D.C. $1298 \mathrm{p}$.

BAlOGH, D.T., CURVElO, A.A.S., GROOTE, R.A.M.C. Solvent effect on organosolv lignin from Pinus caribaea hondurensis (part I). In: BRAZILIAN SYMPOSIUM ON THE CHEMISTRY OF LIGNINS AND OTHER WOOD COMPONENTS, 1, 1989, São Carlos. Proceedings... São Carlos: Universidade de São Paulo, 1989. p. 313-320.

BARTON II, F.E., AKIN, D.E. 1977. Digestibility of delignified forage cell walls. J. Agric. Food Chem., 25:1299.

BJORKMAN, A. 1956. Studies on finely divided wood. I. Extraction with neutral solvents. Svensk. Papperstidning, 59:477.

BRILlOVET, J.M., RIOCHET, D. 1983. Cell wall polysaccharides and lignin in cotyledons and hulls of seeds from various lupin (Lupinus sp.) species. J. Sci. Food Agric., 34:861-868.

CARPITA, N.C., GIBEAUT, D.M. 1993. Structural models of primary cell walls in flowering plants: consistency of molecular structure with the physical properties of the walls during growth. Plant J., 3:1.

DEHORITY, B.A., JOHNSON, R.R. 1961. Effect of particle size upon the in vitro cellulose digestibility of forages by rumen bacteria. J. Dairy Sci., 44:2242.

FAICHNEY, G.J. 1975. The use of markers to partition digestion within the gastrointestinal tract of ruminants. In: McDONALD, I.W., WARNER, A.C.I. (Eds.) Digestion and metabolism in the ruminant tract. Armidale: Univ. New England Publ. Unit.. p.277-291.

FENGEL, D., WEGENER, G.L. 1989. Wood - chemistry, ultrastructure and reactions. Berlin: Walter de Gruyter. $613 \mathrm{p}$.

FUKUSHIMA, R.S. Modification of a colorimetric analysis for lignin and its use in studying the inhibitory effect of lignin on forage digestion by ruminal microorganisms. Columbus, OH: OSU, 1989. 125p. Thesis (Ph.D. in Animal Nutrition) - The Ohio State University, 1989.

FUKUSHIMA, R.S., DEHORITY, B.A., LOERCH, S.C. 1991. Modification of a colorimetric analysis for lignin and its use in studying the inhibitory effect of lignin on forage digestion by rumen microorganisms. J. Anim. Sci., 69:295.

FUKUSHIMA, R.S., DEHORITY, B.A. Feasibility of using lignin isolated from forages by solubilization in acetyl bromide as a standard for lignin analyses. J. Anim. Sci.(no prelo).

FUKUSHIMA, R.S., GARIPPO, G., HABITANTE, A.M.Q.B. et al. Extração da lignina e emprego da mesma em curvas de calibração para a mensuração da lignina em produtos vegetais. Rev. bras. zootec. (no prelo).

GOERING, G.K., VAN SOEST, P.J. 1970. Forage fiber analysis (apparatus, reagents, procedures and some applications). Washington, D.C.: USDA Agr. Handbook n. 379.

HARTLEY, R.D., JONES, E.C. 1977. Phenolic components and degradability of cell walls of grass and legume species. Phytochemistry, 16:1531.

HATFIELD, R.D., JUNG, H.G., RALPH, J. et al. 1994. A comparison of the insoluble residues produced by the klason lignin and acid detergent lignin procedures. J. Sci. Food Agric., 65:51.

IIYAMA, K., WALLIS, A.F.A. 1990. Determination of lignin in herbaceous plants by an improved acetyl bromide procedure. J. Sci. Food Agric., 51:145-161. 
996 Rev. bras. zootec.

JUNG, H.G., VOGEL, K.P. 1986. Influence of lignin on digestibility of forage cell wall material. J. Anim. Sci., 62:1703.

LOWRY, J.B., CONLAN, A.C., SCHLINK, A.C. et al. 1994. Acid detergent dispersible lignin in tropical grasses. J. Sci. Food Agric., 65:41-49.

McDOUGALL, G.J., MORRISON, I.M., STEWART, D. et al. 1996. Plant cell walls as dietary fibre: range, structure, processing and function. J.Sci. Food Agric., 70:133.

MORRISON, I.M. 1972a. A semi-micro method for the determination of lignin and its use in predicting the digestibility of forage crops. J. Sci. Food Agric., 23:455.

MORRISON, I.M. 1972b. Improvements in the acetyl bromide technique to determine lignin and digestibility and its application to legumes. J. Sci. Food Agric., 23:1463.

MORRISON, I.M. 1973. Isolation and analysis of lignincarbohydrate complexes from Lolium multiflorum. Phytochemistry, 12:2979.

MORRISON, I.M. 1983. The effect of physical and chemical treatments on the degradation of wheat and barley straws by rumen liquor-pepsin and pepsin-cellulose systems. J. Sci. Food Agric., 34:1323.

PEPPER, J.M., BAYLIS, P.E.T., ADLER, E. 1959. The isolation and properties of lignins obtained by acidolysis of spruce and aspen woods in dioxane-water medium. Can. J. Chem., 37:1241-1248

ROSSINI, E.L., OLIVEIRA, M.R.G., CURVELO, A.A.S. et al. Lignins extracts by organic solvents: an extension of Brauns lignin. In: BRAZILIAN SYMPOSIUM ON THE CHEMISTRY OF LIGNINS AND OTHER WOOD COMPONENTS, 1, 1989, São Carlos. Proceedings... São Carlos: Universidade de São Paulo, 1989. p.305-312.

STATISTICAL ANALYSIS SYSTEM INSTITUTE INC. 1985. SAS user's guide: statistics. 5.ed., Cary: SAS Institute. 956p.
SHARMA, U., BRILLOVET, J.M., SCALBERT, A. et al. 1986. Studies on a brittle stem mutant of rice, Oriza sativa L. characterization of lignin fractions, associated phenolic acids and polysaccharides from rice stem. Agronomie, 6:265-271.

SHIMOJO, M., GOTO, I. 1984. A study on the relation between disappearance of dry matter and acetyl bromide lignin of tropical grass. Jpn. J. Zootec. Sci., 55:838.

VAN SOEST, P.J. 1963. Use of detergents in the analysis of fibrous foods. II. A rapid method for the determination of fibre and lignin. J. Assoc. Off. Anal. Chem., 46:829.

VAN SOEST, P.J., ROBERTSON, J.B. 1980. Systems of analysis for evaluating fibrous feeds. In: PIGDEN, W.J., BALCH, C.C., GRAHAM, M. (Eds.) Standardization of analytical methodology for feeds. Ottawa: International Development Research Centre. p.49-60.

VAN SOEST, P.J., WINE, R.H. 1968. The determination of lignin and cellulose in acid-detergent fibre with permanganate. J. Assoc. Off. Anal. Chem., 52:780.

VAN SOEST, P.J. 1994. Nutritional ecology of the ruminant. 2.ed. Ithaca: Cornell University Press. 476p.

VILES JR., F.J., SILVERMAN, L. 1949. Determination of starch and cellulose with anthrone. Anal. Chem., 21:950.

WILSON, L.G., FRY, J.C. 1986. Extensin - a major cell wall glycoprotein. Plant Cell Environ., 9:239.

Recebido em: 12/05/1999

Aceito em: 12/01/2000 